\title{
A visão do aluno na utilização do FlipENEM: uma plataforma em fliperama com questões do ENEM
}

\author{
Lívia Silva Marques' ${ }^{1}$, Matheus da Silva Coelho ${ }^{1}$, Larissa Sorato Magnus ${ }^{1}$, Luhan \\ da Silva Nunes ${ }^{1}$, Victor Martins de Sousa ${ }^{2}$, Matheus Lorenzato Braga² \\ ${ }^{1}$ Alunos - Técnico em Informática Integrado ao Ensino Médio - Instituto Federal \\ Catarinense - Campus Avançado Sombrio CEP 88960-000 - Sombrio - SC - Brasil \\ 2 Docentes - Técnico em Informática Integrado ao Ensino Médio - Instituto Federal \\ Catarinense - Campus Avançado Sombrio CEP 88960-000 - Sombrio - SC - Brasil \\ \{liviasmqs, mathcoelho07, larissa15sorato luhan.silvabr\}@gmail.com, \\ \{victor.sousa, matheus.braga\}@ifc.edu.br
}

\begin{abstract}
This paper points the results perceived by students in the use of a video game arcade whose game is intended to prepare for the National High School Examination (ENEM). Structured by an initial research on the impacts of technology on education and the students' real interest in using a game like the one proposed, FlipENEM was developed based on hardware, programming, database and network knowledge and had the results confirmed by means of another research. In addition, was developed in a wooden structure, with buttons and joystick forming a arcade. Through the use of the FlipENEM by the students, positive results were obtained on the platform and also, in relation to its contribution in stimulating the students to the preparation for the ENEM.
\end{abstract}

Resumo. O presente artigo aponta os resultados percebidos por alunos na utilização de um fliperama cujo jogo é destinado à preparação para o Exame Nacional do Ensino Médio (ENEM). Estruturado por uma pesquisa inicial acerca dos impactos da tecnologia na educação e do real interesse dos alunos em utilizar um jogo como o proposto, o FlipENEM foi desenvolvido com base em conhecimentos de hardware, programação, banco de dados e redes e teve os resultados confirmados por meio de outra pesquisa. Além disso, foi desenvolvido em uma estrutura de madeira, com botões e joystick formando um fliperama. Através da utilização do FlipENEM pelos alunos, obteve-se resultados positivos sobre a plataforma e também, em relação à sua contribuição em estimular os estudantes à preparação para o ENEM.

\section{Introdução}

No Brasil, um dos principais exames presentes na vida dos estudantes é o Exame Nacional do Ensino Médio (ENEM), que avalia o conhecimento obtido durante os anos anteriores de estudo e auxilia no ingresso às universidades por meio da nota recebida. Por ser de grande importância, os alunos buscam formas de se preparar dentro e fora da escola, sendo que dentro dela encontram geralmente aulas preparatórias e provas simuladas e fora podem exercitar seus conhecimentos por meio de jogos educacionais, como lembra Alves (2015, p.189) ao dizer que "existem empresas especializadas em desenvolver aplicativos, estratégias metodológicas gamificadas, que podem auxiliar o estudo para exames como o ENEM”. 
A existência desses jogos voltados à preparação para o ENEM é decorrente da crescente presença da tecnologia nos mais diversos setores da vida da maioria das pessoas e principalmente dos jovens. O sociólogo Philippe Perrenoud (2010, p.125) diz que "a escola não pode ignorar o que se passa no mundo", evidenciando a importância da adesão aos novos recursos como, por exemplo, a tecnologia atualmente.

Sancho (2006, p.19) diz que "o computador, assim como o cinema, a televisão e os videogames, atrai de forma especial a atenção dos mais jovens”, o que torna a união da tecnologia à preparação para o ENEM uma situação vantajosa, tendo em vista que cada vez mais a atenção dos jovens é direcionada às novidades e muitas vezes dispersada dos estudos. Essa é, portanto, a motivação para o desenvolvimento do FlipENEM, de maneira que se constitua um novo e atraente método de preparação para o exame.

\section{Metodologia}

A primeira fase de desenvolvimento do FlipENEM foi baseada na investigação do interesse dos estudantes em utilizar uma plataforma como a proposta. Na pesquisa, realizada no Instituto Federal Catarinense - Campus Avançado Sombrio (IFC - CAS), 90,6\% dos entrevistados (alunos de três turmas da terceira série do ensino médio) declararam considerar interessante a ideia de ter um jogo com questões do ENEM dentro da escola. Unindo as informações obtidas, também pôde-se verificar que os alunos, em sua maioria, não buscam esse tipo de recurso para baixar em dispositivos móveis ou utilizar uma ferramenta online, mas gostariam que ele estivesse disponível na escola.

Após confirmar o interesse dos estudantes na plataforma, foi possível iniciar o desenvolvimento do jogo. Para tanto, a linguagem de programação JAVA foi utilizada e o código escrito no ambiente de desenvolvimento integrado NetBeans, formando o layout e a parte funcional do jogo em um computador pessoal. Para o armazenamento de dados das questões (enunciados e alternativas), das informações necessárias para cadastro de usuários (nome, CPF, curso) e do desempenho dos jogadores foi utilizado o Sistema Gerenciador de Banco de Dados MySQL Server.

O jogo, inicialmente desenvolvido em um notebook pessoal, foi avaliado positivamente por professores da área e, então, pôde passar para a fase de instalação na plataforma de fliperama, o qual foi instalado em um computador de mesa disponibilizado pelo IFC - CAS e acoplado à estrutura de madeira.

Os materiais do fliperama (estrutura, botões, joystick e cabos de conexões) foram adquiridos pelos autores por questão de tempo, já que seria inviável cumprir os prazos estipulados para o projeto através da requisição de materiais por meio da instituição. A estrutura de madeira foi feita sob medida para o tamanho do computador disponibilizado e considerava os espaços necessários para os botões e o joystick. Sendo assim, com a instalação de todos os componentes, a plataforma FlipENEM estava pronta.

\section{Resultados}

Com a montagem do fliperama concluída, este ficou disponível para utilização dentro da escola por um período de seis meses e quinze dias, atraindo cada vez mais jogadores: inicialmente eram 164 cadastrados e, ao final da utilização, resultaram 186 jogadores. A figura 1, abaixo, apresenta o formato final da plataforma. 


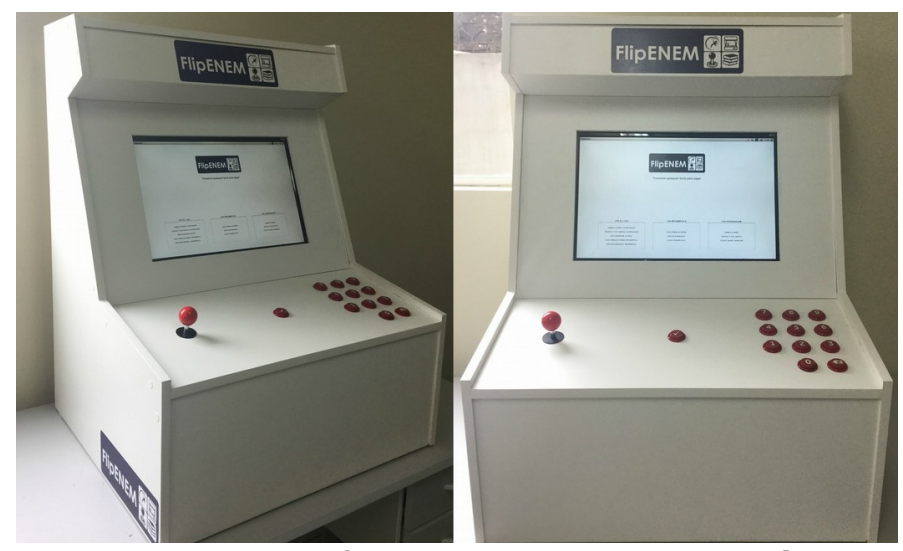

Figura 1: plataforma FlipENEM concluída.

Após o período de utilização, os alunos responderam um segundo questionário, o qual pretendia verificar quais resultados o FlipENEM trouxe na experiência de cada um. Este questionário realizado no ano de 2017 foi respondido por 233 estudantes, divididos entre aqueles que utilizaram a plataforma e os que não utilizaram também, sendo que entre este último grupo, $71,7 \%$ respondeu que gostaria de ter utilizado. Ambos os grupos responderam sobre a aparência do fliperama e 91\% dos 233 concordou que é atrativa, confirmando, assim, uma das principais características do projeto.

Para os estudantes que utilizaram a plataforma, foi questionado se a utilização do jogo trouxe alguma contribuição no processo de preparação para o ENEM, ou não. Podendo escolher entre "Sim, me adaptei ao modelo de questão proposto pelo exame", "Sim, exercitei meus conhecimentos e percebi em qual área do conhecimento tenho mais facilidade ou dificuldade”, "Sim, aprendi com o jogo" e "Não”, e assinalar mais de uma opção, apenas 8 dos 141 alunos declararam não perceber nenhum ganho com a utilização. A figura 2, abaixo, apresenta a distribuição das demais respostas.

\section{Você acredita que a utilização do FlipENEM contribuiu de alguma forma para a preparação para o ENEM?}

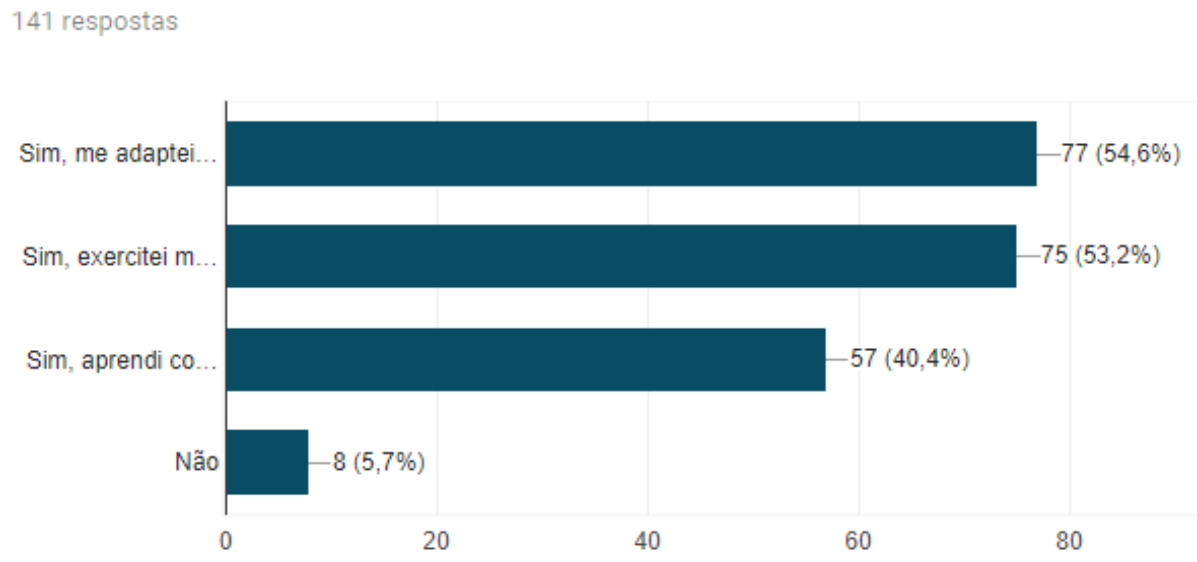

Figura 2: A observância (ou não) de contribuições na preparação para o ENEM com a utilização do fliperama. 
Já no ano de 2018, a fim de dar continuidade ao projeto, como sugerido por grande parte da comunidade escolar do IFC - CAS, os alunos que utilizaram o FlipENEM no ano anterior foram convidados a responder algumas outras perguntas. Entre elas, o questionamento: "se você não tivesse utilizado o FlipENEM ano passado, teria tido contato com outro método de preparação para o exame?”. Como resultado dos 162 respondentes, alunos da primeira e segunda série em 2017, 103 afirmaram que o FlipENEM foi o único método de preparação para o exame antes da prova.

\section{Considerações finais}

Com os resultados obtidos, percebe-se que a utilização do FlipENEM é tida, de modo geral, como positiva pela perspectiva do aluno, principal foco desse projeto.

Considerando que os alunos possuem preferências e entendimentos diferentes sobre os métodos de preparação para o ENEM, o projeto apresenta uma nova ferramenta com essa finalidade, de forma que alunos sem muita afinidade com os métodos tradicionais e/ou aqueles que se interessam pelo formato de jogo, tenham uma ferramenta diferenciada para essa finalidade. Salienta-se, então, que a plataforma desenvolvida não representa um método capaz de substituir as aulas preparatórias (os chamados “aulões"), tampouco os simulados, mas sim uma forma de acrescentar na preparação e auxiliar também os professores, já que o sistema pode indicar quais questões e áreas do conhecimento apresentam maior percentual de erro nas respostas.

Como projeções futuras, identificadas pelos desenvolvedores e também por alguns alunos usuários, pode-se citar: a melhoria no design e estrutura, visando tornar o jogo ainda mais atrativo; a expansão da ideia para outras provas como os vestibulares de interesse dos estudantes; a adaptação da estrutura para que se possam utilizar materiais recicláveis e/ou materiais obsoletos, como caça-níqueis apreendidos que não possuem mais utilidade.

\section{Referências}

ALVES, Lynn. (2015).Aprendizagem mediada pelos jogos digitais - delineando o design investigativo. In: Educação, Tecnologia \& Inovação. Salvador: Edifba.

PERRENOUD, P. . (2000) Dez novas competências para ensinar. Porto Alegre: Artes médicas.

SANCHO, J. M. . (2006) De Tecnologias da Informação e Comunicação a Recursos Educativos. In: Tecnologias para transformar a educação. Porto Alegre: Artmed. 